This item was submitted to Loughborough's Research Repository by the author.

Items in Figshare are protected by copyright, with all rights reserved, unless otherwise indicated.

\title{
Biofilm development by Listeria innocua in turbulent flow regimes
}

PLEASE CITE THE PUBLISHED VERSION

PUBLISHER

(C) Elsevier

LICENCE

CC BY-NC-ND 4.0

\section{REPOSITORY RECORD}

Perni, Stefano, Suzanne J. Jordan, Peter W. Andrew, and Gilbert Shama. 2008. "Biofilm Development by Listeria Innocua in Turbulent Flow Regimes". figshare. https://hdl.handle.net/2134/3479. 
This item was submitted to Loughborough's Institutional Repository by the author and is made available under the following Creative Commons Licence conditions.

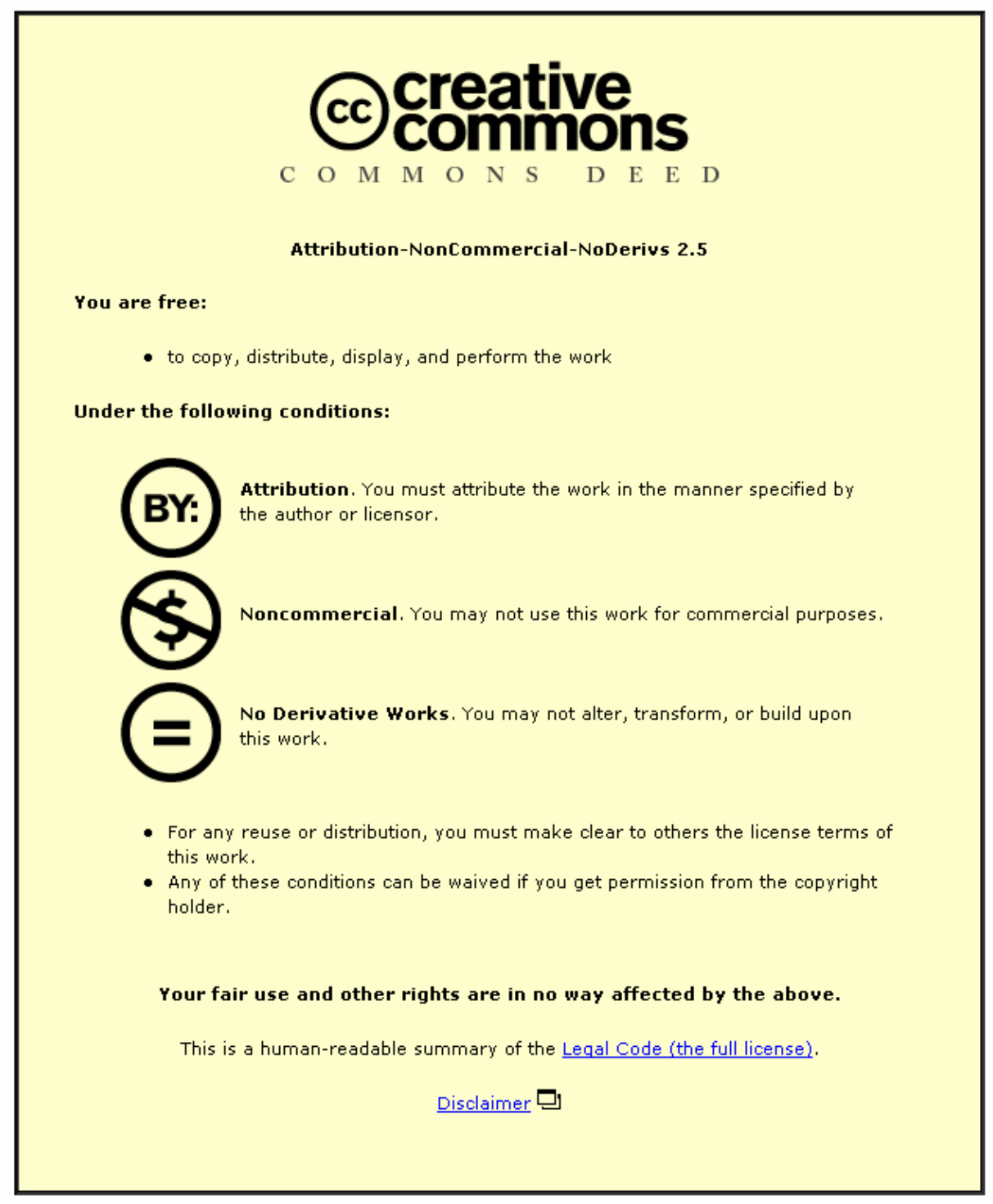

For the full text of this licence, please go to: http://creativecommons.org/licenses/by-nc-nd/2.5/ 


\section{BIOFILM DEVELOPMENT BY LISTERIA}

\section{INNOCUA IN TURBULENT FLOW REGIMES}

4 Stefano Perni ${ }^{1}$, Suzanne J. Jordan ${ }^{2}$, Peter W. Andrew ${ }^{2}$, Gilbert Shama ${ }^{1}$

5

$6{ }^{1}$ Department of Chemical Engineering, Loughborough University, Loughborough,

$7 \quad$ LEICS., LE11 3TU, U.K.

$8 \quad{ }^{2}$ Department of Infection, Immunity and Inflammation, Leicester University,

9 Leicester, LEICS., LE1 9HN, U.K.

10

11 Corresponding author:

12 Dr. Gilbert Shama

13 Department of Chemical Engineering

14 Loughborough University

15 Loughborough

16 LE11 3TU

17 U.K.

18

19 G.Shama@lboro.ac.uk Tel: + 44 (0)1509 222514 Fax: + 44 (0)1509 223923

20 Key words: Listeria innocua, biofilm, Reynolds number 


\section{ABSTRACT}

22 Chemostat-cultured cells of $L$. innocua were continuously recirculated through a

23 stainless steel tubes at Reynolds numbers ranging from 9,500 to 16, 500 for 7 days.

24 Samples of the tubes were removed by a special method and were examined using

25 SEM. Biofilm formation had occurred after only 1 day at Reynolds numbers of 9,500

26 and 11,500 and the extent of coverage increased with time. At the higher Reynolds

27 numbers (13,000 and 16,500) only individual cells were evident after 1 day, but these

28 developed to form microcolonies. After 7 days biofilms had become established at all 29 four Reynolds numbers. 
Food may become microbiologically contaminated simply by contact with abiotic surfaces that are themselves colonised by pathogenic micro-organisms (Midelet \& Carpenter, 2002; Lundén, Autio \& Korkeala, 2002; Midelet \& Carpentier; 2004). The transfer of micro-organisms will depend on the state of the micro-organisms at the surface. Individual cells may simply adsorb to a surface or proliferate at the surface in the form of a biofilm. A biofilm has been defined as a functional consortium of micro-organisms attached to a surface and is embedded in the extracellular polymeric substances (EPS) produced by micro-organisms (Costerton et al., 1978). Biofilms present a greater threat to food safety because they are capable of self-regeneration if portions of the biofilm become detached or 'sloughed off' (Carpentier \& Cerf, 1993), and because they are resistant to chemical disinfection

Bacterial attachment studies are typically conducted under conditions where there is no gross flow of liquid relative to the surface (Norwood \& Gilmour, 1999; Beresford, Andrew \& Shama, 2001). Whilst such studies have undoubtedly contributed to an understanding of the phenomenon of attachment, there are many circumstances in

51 both natural and artificial environments where solid surfaces are either continuously, or periodically, in contact with flowing liquids that contain micro-organisms. Fluid

53 flows are characterised by a dimensionless parameter known as the Reynolds number.

54 The Reynolds number (Re) is defined as $\rho v D / \mu$ where, $\rho$ is the fluid density, $v$ its 
velocity, D a characteristic dimension and $\mu$ the fluid viscosity. In practical terms this parameter represents the ratio of inertial to viscous flow; values below about 2,000 are termed laminar whilst those above 4,000 are turbulent.

The trend in industrialized countries is for food processing to become increasingly centralized (Hjaltested, Gudmundsdottir, Jonsdottir, Kristinsson, Steingrimsson, \& Kristajansson, 2002; Wing \& Gregory, 2002). As a result of this, processing facilities increase in scale and operations such as cleaning become fully automated. Such changes are inevitably accompanied by increases to the flow rates - and concomitantly Reynolds numbers - of ingredients and products. Despite these trends, surprisingly little work has been done on the formation of biofilms at high Reynolds numbers. Previous studies have focussed on the pseudomonads because certain species such as $P$. putida and $P$. fluorescens are good biofilm formers (Pujo \& Bott, 1991; Melo \& Viera, 1994; Lewandowski \& Stoodley, 1995; Stoodley, Lewandowski, Boyle \& Lappin-Scott, 1998).

An additional feature of many previous studies on biofilm formation has been the use of translucent abiotic surfaces such as glass or certain synthetic polymers because this aids in the visualisation of the biofilms. In fact these materials are rarely employed in the modern food industries: glass is fragile, and when it breaks fragments can potentially contaminate foods. Whilst polymers are unsuitable in any applications where their surfaces might become scratched because this can encourage biofilm formation (van Haecke, Remon, Moors, Raes, Derudder \& Vanpeteghem, 1990). Stainless steel on the other hand is widely used in the food industry owing to its excellent corrosion resistance and because it is able to withstand the cleaning and 
80 sanitising regimes routinely employed in the food industry (Zottola \& Sasahara, 81 1994).

82

83 Tubes represent a particularly convenient means of contacting microbial suspensions

84 with solid materials, but accessing the lumen of tubes is difficult particularly if the

85 tubes are made of hard materials such as steel. In the work presented here we

86 describe a method for monitoring biofilm formation in stainless steel tubes through

87 which were continuously recirculated chemostat-grown culture of L. innocua at

88 Reynolds numbers ranging from 9,500 to 16,500. 
Bacterium - Maintenance and Cultivation

91 Listeria innocua (ATCC 33090) was purchased from the National Collection of Type

92 Cultures, Colindale, Middx. Cultures were maintained on Brain Heart Infusion agar

93 (Oxoid, Basingstoke, U.K.) slopes at $4{ }^{\circ} \mathrm{C}$. L. innocua was grown both in shake flasks

94 and in a chemostat on a Tryptone -Yeast medium having the following composition:

95 Glucose 0.50 g, $\mathrm{NaCl} 15.00$ g, $\mathrm{NaH}_{2} \mathrm{PO}_{4} 0.50 \mathrm{~g}, \mathrm{Na}_{2} \mathrm{HPO}_{4} 0.50 \mathrm{~g}, \mathrm{MgSO}_{4} \cdot 7 \mathrm{H}_{2} \mathrm{O}$

$96 \quad 0.15 \mathrm{~g}$, Yeast extract $2.50 \mathrm{~g}$, Tryptone $2.50 \mathrm{~g}$. (All quantities per litre of distilled

97 water). The medium was sterilised by autoclaving at $121^{\circ} \mathrm{C}$ for 15 minutes.

98 Chemostat

99 Listeria innocua was grown in a fully instrumented bioreactor operated as a

100 chemostat. The bioreactor (FT Applikon, Gloucester, U.K.) was operated at a working

101 volume of 1 litre. Temperature control $\left(30 \pm 0.5^{\circ} \mathrm{C}\right)$ was maintained by placing the

102 bioreactor in a temperature controlled water bath. $\mathrm{pH}$ was maintained and controlled

103 at 7.0 by the automated addition of either $0.2 \mathrm{M} \mathrm{NaOH}$ or $0.2 \mathrm{M} \mathrm{HCl}$. Air was

104 supplied to the sparger at a flow rate of 1.3 litres $\min ^{-1}$ and the impeller was operated

105 at $200 \mathrm{rpm}$. The dilution rate was kept constant at $0.015 \mathrm{hr}^{-1}$ and steady state was

106 deemed to have been reached after at least five volume throughputs. Daily checks

107 were made for contamination by examination of culture samples using a microscope

108 and by plating on Palcam Agar (Oxoid) and Tryptone Soya Agar (Oxoid), and

109 incubating at $30^{\circ} \mathrm{C}$, and Malt Extract Agar (Oxoid), and incubating at $25^{\circ} \mathrm{C}$, and

110 examining the plates daily for 3 days. In all cases samples were taken directly from

111 the bioreactor.

112 Cell Counts 
113 Samples from the chemostat were serially diluted in $1 / 4$ strength Ringers solution and

114 plated onto Tryptone Soy Agar (Oxoid). The plates were incubated overnight at $30^{\circ} \mathrm{C}$

115 before counting.

116 Biofilm Apparatus

117 A schematic of the apparatus used to study biofilm formation is given in

118 Figure 1. Culture from the chemostat was fed directly into a 2 litre stirred mixing

119 vessel located in a water bath and maintained at $30^{\circ} \mathrm{C}$ by means of a chilling unit

120 (CZ1, Grant Instruments, Cambridge, U.K.) equipped with a temperature controller

121 ('Fi-monitor’, Fisons Ltd., Loughborough, U.K.). Cell suspension was circulated

122 through test sections and via a coiled tube heat exchanger by means of a centrifugal

123 pump (Model JP5, Grundfos Pumps Ltd., Leighton Buzzard, U.K.) installed with a

124 by-pass line. The volume of liquid in suspension was approximately 7 litres. The

125 stainless steel tubes (AISI 304, length, 1 m, O.D., $0.012 \mathrm{~m}$ and I.D., $0.01 \mathrm{~m}$; East

126 Midlands Alloys, Loughborough, U.K.) were mounted in a specially-designed

127 manifold.

128 Overall flow to the manifold was controlled by means of the pump by-pass valve but

129 the flow to each tube was set by means of a ball valve. The flowrate to each tube was

130 measured by means of orifice plates equipped with differential pressure transducers.

131 The liquid volume in the mixing vessel was maintained constant by means of a

132 peristaltic pump (Model 302S, Watson-Marlow Ltd, Falmouth, UK).

133 Sanitisation Protocol

134 All equipment downstream of the chemostat was sanitised by the continuous

135 recirculation for 24 hours of a biocide solution (RBS pF, Borghgraef S. A., Belgium).

136 Following this the biocide was drained out and the apparatus was flushed through 
with 100 litres of tap water sterilised by passage through a $0.2 \mu \mathrm{m}$ in-line filter (Sartoclean CA, Sartorius, Epsom, Surrey, U.K.).

\section{Treatment of test sections}

Removable test sections $0.05 \mathrm{~m}$ long were located in each of the $1 \mathrm{~m}$ stainless steel pipes $0.1 \mathrm{~m}$ from the ends by means of push fit couplings (Flow-Tech, Loughborough, U.K.). This was within the region of fully developed flow at each of the Re used.

\section{Before replacing the test sections, the system downstream of the chemostat was}

drained and the liquid collected in pre-sterilised vessels. After the new sections had been inserted into place the bacterial suspension was re-introduced into the mixing vessel and circulation was resumed.

Prior to connection, the test sections were grooved to enable small coupons ( 1 x $10^{-2}$ by $5 \times 10^{-3} \mathrm{~m}$ ) to be cut from them once they were removed from the stainless steel tubes without unduly disturbing the biofilm colonising the bore of the section. Four equidistant longitudinal grooves (length, $0.01 \mathrm{~m}$ ) were milled into the outside of the test sections (figure $2 \mathrm{a})$. The depth of the grooves $\left(8 \times 10^{-4} \mathrm{~m}\right)$ was such as to permit ready detachment of the coupon whilst at the same time allowing the test section to retain strength and rigidity whilst in location in the biofilm apparatus. Once removed from the biofilm apparatus, the test sections were first washed in sterile phosphate buffer solution (PBS) to removed unattached cells. They were then fixed in $2 \%$ glutaraldehyde (buffered with PBS) for 2 hours and finally washed three times in PSB for 15 minutes.

In order to provide coupons for examination by SEM, the ungrooved portions of the test sections were cut away using a pipe cutter (Figure 2b) and a fine saw was used to make two longitudinal cuts (figure 2c) that resulted in the detachment of a coupon having a curved surface (figure 2d). 
162 Coupons were stored in PBS at $4{ }^{\circ} \mathrm{C}$ before being analyzed by SEM. Coupons were 163 never stored for more than 4 days.

164 Preparation for SEM

165 SEM was chosen as it can be used for the examination of surfaces that are not flat, 166 however it does not allow in vivo studies and some artifacts can be generated (Surman 167 et al., 1996). Coupons were prepared for Scanning Electron Microscopy (SEM) by 168 first washing in distilled water for 5 minutes. They were then dehydrated in alcohol 169 of increasing strength, starting with $70 \%$ followed by $90 \%$ and finally absolute 170 alcohol, exposure in all cases being for 10 minutes. Then the samples underwent a 171 critical point drying (Baltec CPD 030 Critical Point Dryer, EM Systems Support Ltd, 172 Cheshire, UK) and then they were sputter-coated with gold for 90 seconds at 20mA 173 (Polaron SC7640, Quorum Technologies Ltd., Newhaven, UK).

174 All observations were carried out with SEM (Hitachi S3000H - Hitachi Scientific 175 Instruments, London, UK).

\section{RESULTS}

179 Operation of the chemostat under the conditions specified under Materials and 180 Methods led to a steady state concentration of cells in the overflow line of $7.4 \times 10^{9}$ $181 \mathrm{CFU} / \mathrm{ml}$ which was equivalent to an absorbance at $600 \mathrm{~nm}$ of 1.03 . The velocities in 182 each of the four tubes were $0.95 ; 1.15 ; 1.30 ; 1.65 \mathrm{~m} / \mathrm{s}$ which correspond to Reynolds 183 numbers of 9,500, 11,500, 13,000 and 16,500 respectively (based on the properties of 184 pure water at $30^{\circ} \mathrm{C}$ ). The system devised here for sampling the stainless steel tubes 185 proved successful in practice and stainless steel coupons were detached from the test 186 sections in a way that minimised disruption of attached biofilms. SEM images of the 
development of the biofilm at Reynolds numbers ranging from 9,500 to 16,500 after 1, 4 and 7 days are shown in Figures 3 to 5.

L. innocua had colonised a significant proportion of the surface at a Reynolds number of 9,500 after only 1 day (Figure 3a). Increasing the Reynolds number to 11, 500 resulted in less attachment, but appreciable surface colonization is still evident (Figure 3b). However, at a Reynolds number of 13,000 only small aggregates of cells are visible (Figure 3c). Figure 3d reveals a surface largely free of cells at the highest Re of 16,500. After 4 days, the extent of surface attachment at the lower Reynolds numbers, 9,500 and 11,500 (Figures 4a \&b) appears very similar. Figure 4c reveals cell aggregates similar to those seen previously after 1 day. The SEM at the highest Reynolds number, 16,500 (Figure 4d) shows cell clusters where only a previously small numbers of single cells were visible (Figure 3d). By day 7, surface attachment at a Reynolds number of 9, 500 appears to have become more widespread. Surface coverage for the higher Reynolds numbers (Figs 5b-d) seems not significantly different to those obtained after 4 days.

Some of the SEM images reveal the presence of fissures at the surface of the stainless steel. In particular, Figure 4c shows two such fissures at high magnification. It is noticeable that these surface features do not appear to be the focus for cell attachment. In fact the attached growth visible in the figure is quite distinct from the fissures.

The stainless steel tubes and associated pipes, fittings and pumps could only be sanitized rather than sterilized. Therefore the possibility of contamination could not be excluded. However, samples plated out on a variety of agars did not reveal 
obvious contaminants. Examination of the attached cells reveals the presence of low numbers of morphologically distinct cells. Elongated cells are indicated by an arrow in Figure 4c and squat cells by an arrow in Figure 5a.

\section{DISCUSSION}

The techniques developed here enabled samples to be removed from stainless steel tubes without causing obvious damage to the attached biofilms. Using these techniques we were able to demonstrate that $L$. innocua is capable of establishing biofilms in turbulent flow conditions at Reynolds numbers up to 16,500.

The question of whether listerial species can form biofilms was until recently one that had not been resolved. Kalmokoff, Austin, Wan, Sanders, Banerjee \& Farber (2001) claimed that L. monocytogenes does not form true biofilms but merely adheres to surfaces, and most of the visual evidence of surface colonisation published before 2001 would appear to support this view. However, Marsh, Luo \& Wang (2003) provided convincing evidence to the contrary by publishing SEMs of biofilms produced by L. monocytogenes. The studies reported here are the first to demonstrate biofilm formation by a listerial species under flow conditions and at Reynolds

231 numbers that are industrially relevant.

There have been only few previous studies relevant to the food industry performed at such high Reynolds numbers. Pujo \& Bott (1991) operated with Reynolds numbers up to 16, 800 and Lewandowsky \& Stoodley (1995) examined turbulent flows with 
pseudomonads. Lewandowsky \& Stoodley (1995) measured the effect of biofilm

238 formation on pressure drop in pipes and claimed that the pressure drop can double

239 over a period of 25 days. Attempts to measure pressure drop caused by L. innocua

240 biofilms proved unsuccessful (Perni, 2005).

242 Biofilms are often associated with exopolysaccharide (EPS) which is thought to play a 243 role in surface attachment (Stoodley et al., 1999). In general, the SEM images

244 presented here do not reveal unambiguous EPS formation. Fine strands that might be 245 constituted of EPS are visible in the biofilms at 7 days at the lowest Reynolds number

246 (Fig 5a). Similarly, SEMs of biofilms of L. monocytogenes presented by Chavant, 247 Folio \& Hebraud (2003) did not show the presence of EPS matrix.

249 Preliminary experiments (not reported here) conducted in the absence of $\mathrm{NaCl}$ in the 250 growth medium led to rapid contamination of the mixing vessel and of the biofilms 251 that formed on the stainless steel tubes. Supplementing the medium with $\mathrm{NaCl}$ at 1.5 $252 \%$ was successful in eliminating contamination in the mixing vessel. Figures 3 to 5 253 reveal the presence of small numbers of cells with distinctive morphologies. As 254 previously stated, it is possible that these are contaminants. However, there is a 255 alternative explanation for the presence of these cells: Zaika \& Fanelli (2003) applied 256 stresses to growing cultures of L. monocytogenes by manipulating the growth 257 temperature and the concentration of $\mathrm{NaCl}$ added to cultures. These workers were 258 able to achieve elongations of between 4 and 10 times the length of unstressed cells, 259 and also a shortening of cells. The stresses imposed on L. innocua cells attached to 260 stainless steel surfaces in this work are not so readily identified. However, the 261 prevailing conditions were those of constant high hydrodynamic shears and it is not 
inconceivable that this might have manifested itself in changes to the cell morphology

263 of a certain sub population of cells.

264

The results obtained here cast doubt on the 'rule of thumb' widely quoted in industry that velocities of $1 \mathrm{~m} / \mathrm{s}$ are sufficient to prevent biofilm formation (Pujo \& Bott,1991). It was earlier mentioned that biofilm formation carries with it the chance of contamination. Many of the techniques currently being advocated for the decontamination of the surfaces of foods or processing plant such as UV (Gardner \& Shama, 2001) or cold plasma treatment (Vleugels, Shama, Deng, Greenacre, Brocklehurst and Kong, 2005) would benefit from an ability to conduct large scale trials under realistic conditions inside food processing facilities. However, such studies could only be undertaken if it could be guaranteed that public health would not thereby be compromised. Moreover, there is a considerable amount of interest in the elimination of L. monocytogenes from food processing environments (Carpentier \& Chassaing, 2004) but studies of the sort advocated above with this bacterium would not be possible because of the containment requirements that are demanded in most industrialised countries. Indeed, we were not able to repeat the experiments reported here with $L$. monocytogenes because we were unable to provide the necessary containment necessary for the industrial pumps and valves we used.

L. innocua has been used as a surrogate for L. monocytogenes sometimes with little or no stated justification (Wouters, Dutrreux, Smelt \& Lelieveld, 1999) or on the basis that both organisms were similarly resistant to tetracycline, ozone and the bacteriocins produced by Carnobacterium spp., (Vaz-Velho, Fonseca, Silva \& Gibbs, 2001). In

286 addition, both organisms have been shown to have a similar susceptibility to 
antibiotics and heavy metals (Margolles, Mayo \& Reyes-Gavilan, 2001) and to have 288 similar responses to heat treatment, gamma irradiation, lactic acid and sodium nitrite 289 treatment (Kamat \& Nair, 1996). The lone voice of dissent would appear to be that of 290 Meylheuc, Giovannacci, Briandet \& Bellon-Fontaine, (2002) who concluded on the 291 basis of microelectrophoresis and physicochemical surface characterization tests 292 based on microbial adhesion to solvents that the two organisms were dissimilar to the 293 extent that $L$. innocua should not be used as a substitute for $L$. monocytogenes.

295 Notwithstanding, both species have been shown to occupy identical niches in food 296 processing plants (Gudbjornsdottir et al., 2004) and on a variety of foods (Duffy et al., 297 2000; Cornu, Kalmokoff \& Flandrois, 2002). Therefore, the finding that L. innocua 298 forms biofilms on a material widely-used in the food industry under conditions 299 generally regarded as preventing film formation evidently must at the very least 300 increase the possibility that L. monocytogenes also possesses similar biofilm-forming 301 abilities under conditions of high Reynolds numbers flow. 


\section{REFERENCES}

Beresford, M., Andrew, P. W. \& Shama, G. (2001). Listeria monocytogenes adheres to many materials found in food-processing environments. Journal of Applied Microbiology, 90, 1000-1005.

Carpentier, B., \& Cerf, O. (1993). Biofilms and their consequences, with particular reference to hygiene in the food industry. Journal of Applied Bacteriology, 75, 499511.

Carpentier, B., \& Chassaing, D. (2004). Interactions in biofilms between Listeria monocytogenes and resident microorganisms from food industry premises. International Journal of Food Microbiology, 97, 111-122.

Chavant, P., Folio, P. \& Hébraud, M. (2003). Growth of Listeria monocytogenes in biofilm according to the surface and the temperature and effects of different treatments on its survival. Science des Aliments, 23, 116-119.

Cornu, M., Kalmokoff, M. \& Flandrois J.P. (2002). Modelling the competitive growth of Listeria monocytogenes and Listeria innocua in enrichment broths. International Journal of Food Microbiology, 73, 261-274.

Costerton, J.W., Cheng, K.J., Geesey, G.G., Ladd, T.I., Nickel, J.C. Dasgupta, M., \& Marrie, T.J. (1987). Bacterial biofilms in nature and disease. Annual Reviews in Microbiology, 41, 435-464.

Duffy, G., Walsh D., Sheridan J.J., Logue C.M., Harrington D., Blair I.S., \& McDowell D.A. (2000). Behaviour of Listeria monocytogenes in the presence of Listeria innocua during storage of minced beef under vacuum or in air at 0 degrees $\mathrm{C}$ and 10 degrees C. Food Microbiology, 17, 571-578.

Gardner, D.W.M. \& Shama, G. (1999) UV Intensity Measurement and Modelling and Disinfection Performance Predication for Irradiation of Solid Surfaces with UV Light. Food and Bioprocess Engineering, 77, 232-242.

Gudbjornsdottir, B., Suihko, M.L., Gustavsson, P., Thorkelsson, G., Salo S., Sjoberg, A.M., Niclasen, O. \& Bredholt, S. (2004). The incidence of Listeria monocytogenes in meat, poultry and seafood plants in the Nordic countries. Food Microbiology, 21, 217225.

Hammer, B.K., \& Bassler, B.L. (2003). Quorum sensing controls biofilm formation in Vibrio cholerae. Molecular Microbiology, 50, 101-114.

Hjaltested, E.K.R., Gudmundsdottir, S., Jonsdottir, K., Kristinsson, K.G., Steingrimsson, O., \& Kristajansson, M. (2002). Listeriosis in Iceland, 1978-2000:A description of cases and molecular epidemiology. Scandanavian Journal of Infectious Diseases, 34, 735-741. 
Kalmokoff, M.L., Austin, J.W., Wan, X.D., Sanders, G., Banerjee, S. \& Farber, J.M. (2001). Adsorption, attachment and biofilm formation among isolates of Listeria monocytogenes using model conditions. Journal of Applied Microbiology, 91,725-734.

Kamat, A.S., \& Nair, P.M. (1996). Identification of Listeria innocua as a biological indicator for inactivation of $L$. monocytogenes by some meat processing treatments. Lebensmittelindustrie, 29, 714-720.

Klima, R.A., \& Montville, T.J. (1995). The regulatory and industrial-responses to listeriosis in the USA - a paradigm for dealing with emerging foodborne pathogens. Trends in Food Science \& Technology, 6,87-93.

Krysinski, E.P., Brown, L.J., \& Marchisello, T.J. (1992). Effect of cleaners and sanitizers on Listeria monocytogenes attached to product contact surfaces. Journal of Food Protection, 55, 246-251.

Lewandowski, Z. \& Stoodley P. (1995). Flow induced vibrations, drag force, and pressure drop in conduits covered with biofilm. Water Science \& Technology, 32, 1926.

Lundén, J., Autio, T. J. \& Korkeala, H. J. (2002). Transfer of persistent Listeria monocytogenes contamination between food-processing plants associated with dicing machine. Journal of Food Protection, 65, 1129-1133.

Margolles, A., Mayo, B., \& de los Reyes-Gavilan, C.G. (2001). Susceptibility of Listeria monocytogenes and Listeria innocua strains isolated from short-ripened cheeses to some antibiotics and heavy metal salts. Food Microbiology, 18, 67-73.

Marsh, E.J., Luo, H.L. \& Wang, H. (2003). A three-tiered approach to differentiate Listeria monocytogenes biofilm-forming abilities. FEMS Microbiology Letters, 228,203-210.

Melo, L. F. \& Viera, M. J. (1999). Physical stability and biological activity of biofilms under turbulent flow and low substrate concentration. Bioprocess Engineering, 20, 363-368.

Meylheuc, T., Giovannacci, I., Briandet, R. \& Bellon-Fontaine, M.N. (2002). Comparison of the cell surface properties and growth characteristics of Listeria monocytogenes and Listeria innocua. Journal of Food Protection, 65,786-793.

Midelet, G. \& Carpenter, B. (2002). Transfer of microorganisms, including Listeria monocytogenes, from various materials to beef. Applied \& Environmental Microbiology, 68, 4015-4024.

Midelet, G. \& Carpentier, B. (2004). Impact of cleaning and disinfection agents on biofilm structure and on microbial transfer to a solid model food. Journal of Applied Microbiology, 97, 262-270. 
Norwood, D. E. \& Gilmour, A. (1999). Adherence of Listeria monocytogenes strains to stainless steal coupons. Journal of Applied Microbiology, 86, 576-582.

Perni, S. (2005). Listeria innocua -Physiology and biofilm formation, Loughborough University, PhD thesis (in the press).

Prouty, A.M., \& Gunn, J.S. (2003). Comparative analysis of Salmonella enterica serovar typhimurium biofilm formation on gallstones and on glass. Infection and Immunity, 71, 7154-715.

Pujo, M. \& Bott, T. R. (1991). Effects of fluid velocities and Reynolds numbers on biofilm development in water systems. Experimental Heat transfer, Fluid Mechanics and Thermodynamics Eds. Keffer, J.F., Shah, R.K., \& Ganic, E.N. (pp1358-1362) Elsevier, New York.

Ryu, J.H., \& Beuchat, L.R. (2004). Factors affecting production of extracellular carbohydrate complexes by Escherichia coli O157 : H7. International Journal of Food Microbiology, 95,189-204.

Stoodley, P., Lewandowski, Z., Boyle, J. D. \& Lappin-Scott, H. M. (1998).

Oscillation characteristics of biofilm streamers in turbulent flowing water as related to drag and pressure drop. Biotechnology \& Bioengineering 57, 536-544

Stoodley, P., Boyle, J.D., DeBeer, D. \& Lappin-Scott, H.M. (1999).

Evolving perspectives of biofilm structure. Biofouling, 14, 75-+

Van Haecke, E., Remon, J.P., Moors, M., Raes, F., Derudder, D. \& Vanpeteghem, A. (1990). Kinetics of Pseudomonas aeruginosa adhesion to 304 and 316-l stainless-steel - role of cell-surface hydrophobicity. Applied and Environmental Microbiology, 56, 788-795.

Vaz-Velho, M., Fonseca, F., Silva, M. \& Gibbs, P. (2001). Is Listeria innocua 2030c, a tetracycline-resistant strain, a suitable marker for replacing $L$. monocytogenes in challenge studies with cold-smoked fish? Food Control, 12,361-364.

Vleugels, M., Shama, G., Deng, X. T., Greenacre, E., Brocklehurst, T., \& Kong, M.G. (2005). Atmospheric plasma inactivation of biofilm-forming bacteria for food safety control. IEEE Transactionson Plasma Science, (in the press).

Wing, E.J. \& Gregory, S.H. (2002). Listeria monocytogenes: Clinical and experimental update. Journal of Infectious Diseases,185: S18-S24 Suppl.

Wouters, P.C., Dutrreux, N., Smelt, J.P.P.M., \& Lelieveld, H.L.M. (1999). Effects of pulsed electric fields on inactivation kinetics of Listeria innocua. Applied and Environmental Microbiology, 65, 5364-5371.

Zaika, L.L. \& Fanelli, J.S. (2003). Growth kinetics and cell morphology of Listeria monocytogenes Scott A as affected by temperature, $\mathrm{NaCl}$, and EDTA. Journal of Food Protection, 66, 1208-1215. 
Zottola, E.A. \& Sasahara, K.C. (1994). Microbial biofilms in the food-processing industry - should they be a concern? International Journal of Food Microbiology, 23, 125-148. 


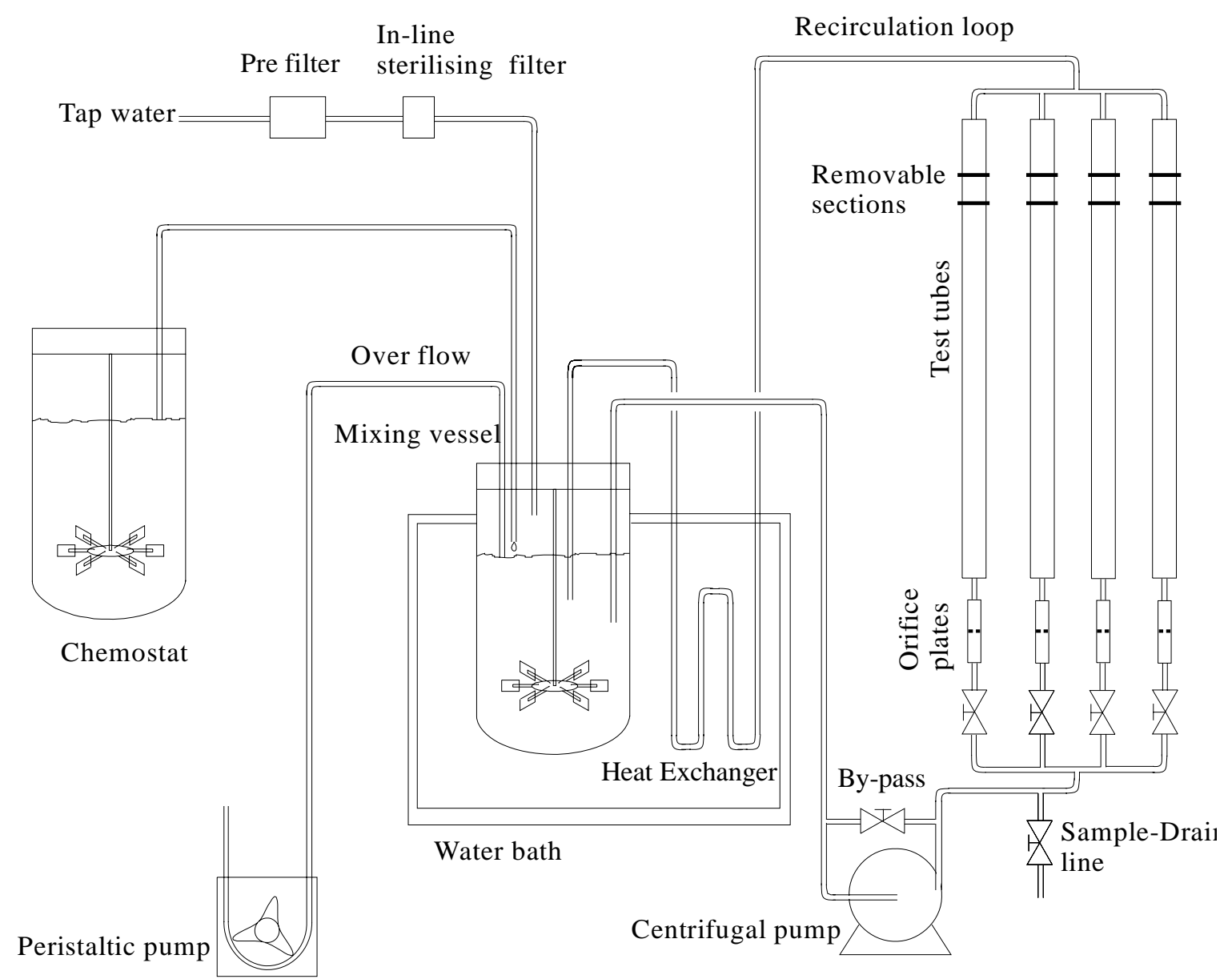

Figure 1 Schematic of the biofilm formation apparatus 


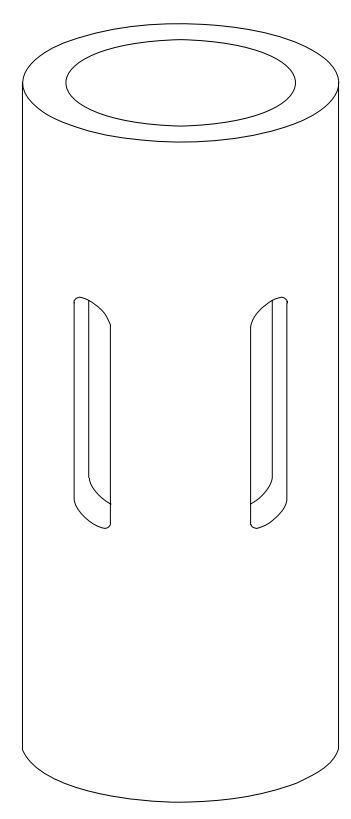

(a)

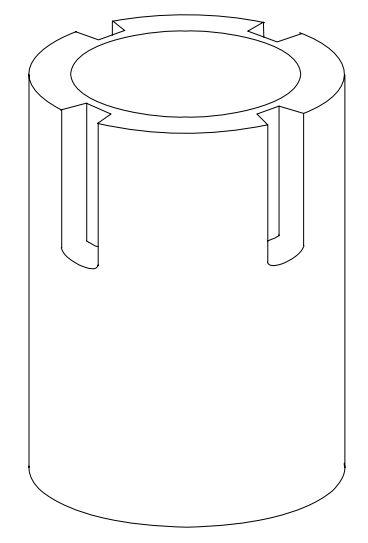

(b)

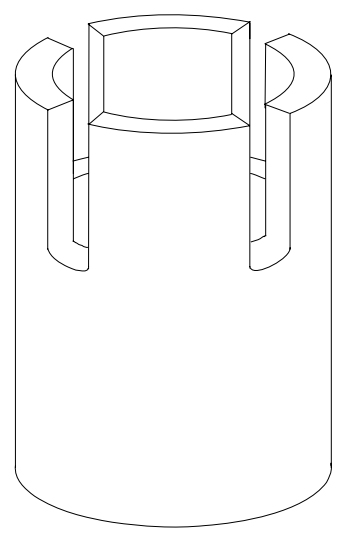

(c)

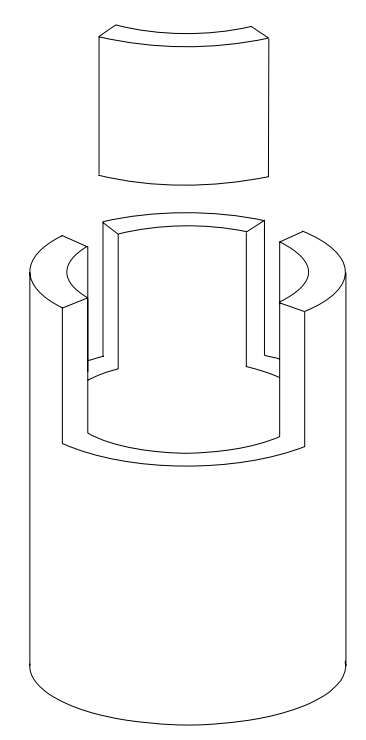

(d)

Figure 2 Stages in the removal of test sections of stainless steel tube for examination by SEM

(a) Test piece showing exterior lateral grooves

(b) Truncation across grooves

(c) Vertical incision

(d) Removal of test piece 

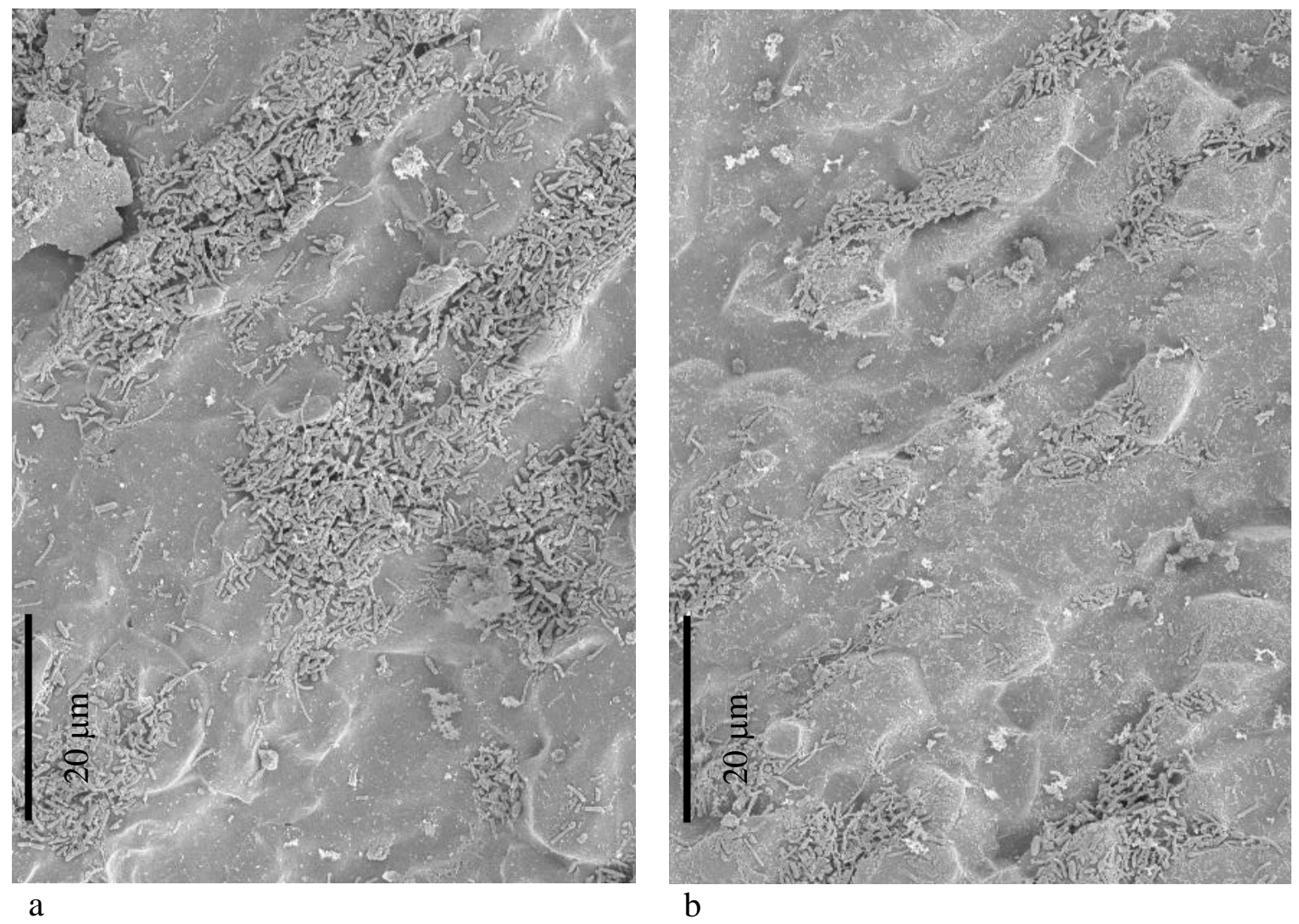

Page 21 of 24 

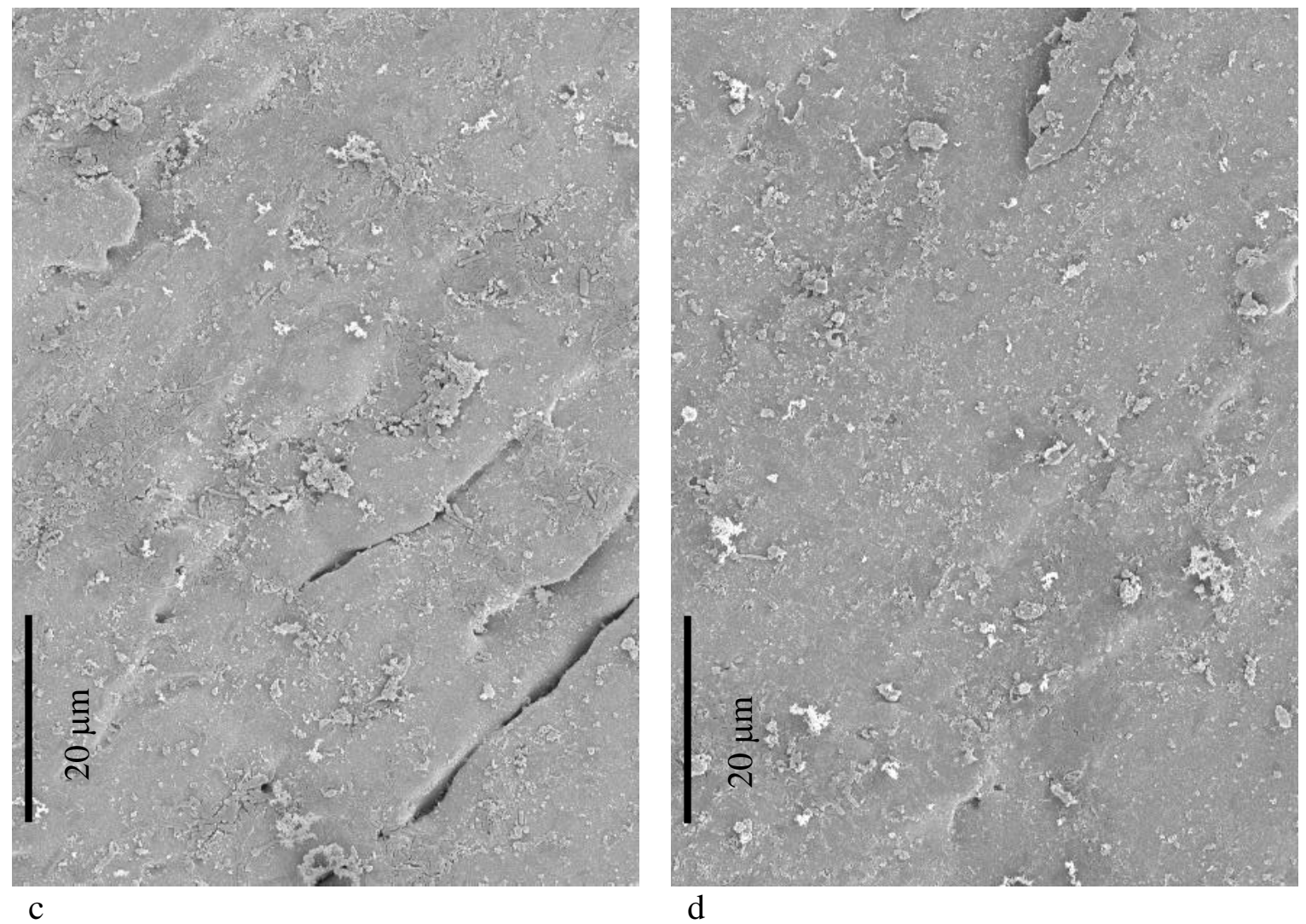

Figure 3 L. innocua biofilms after 1 day

$(a \operatorname{Re}=9,500 ; b \operatorname{Re}=11,500 ; c \operatorname{Re}=13,000 ; d \operatorname{Re}=16,500)$ 

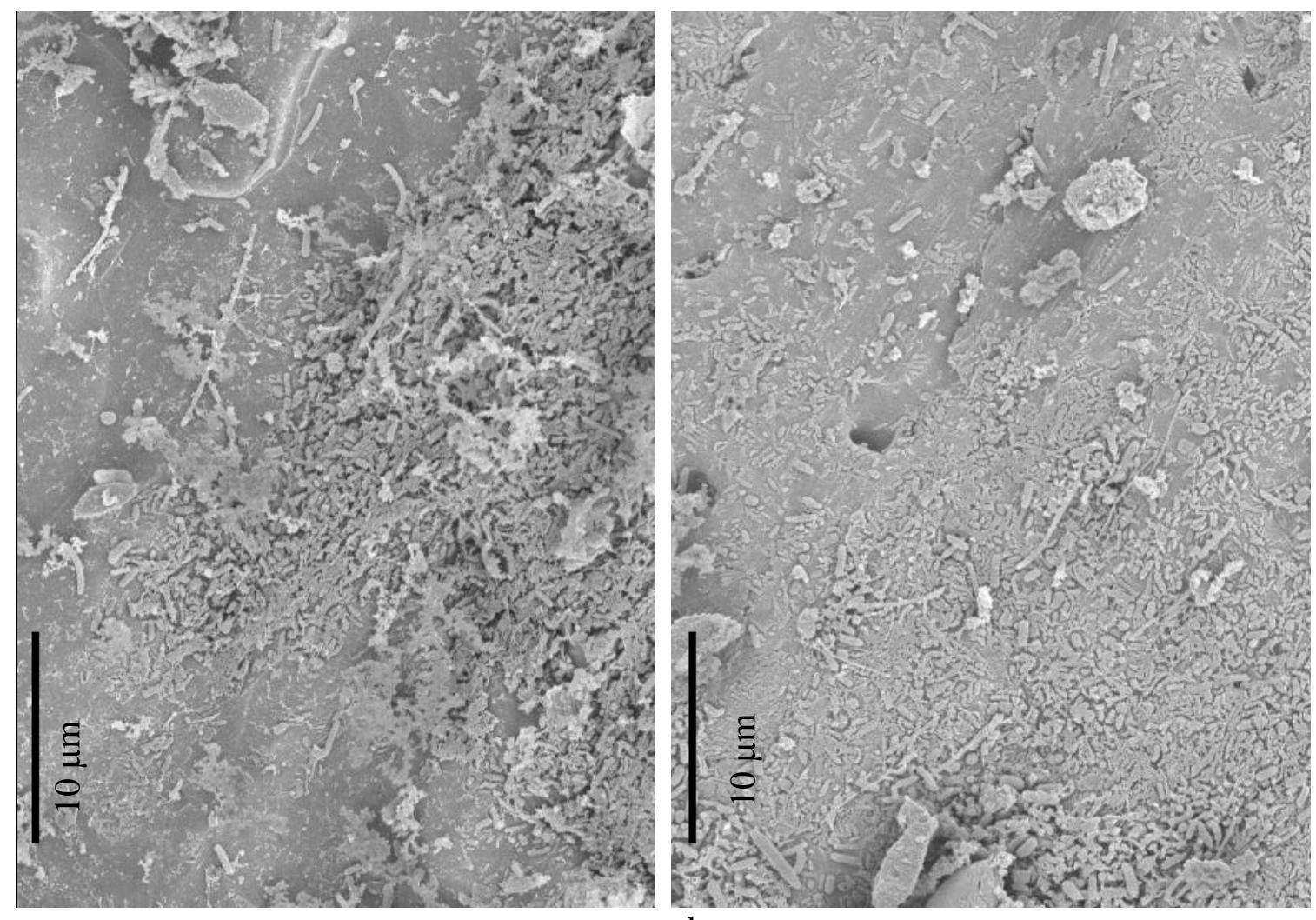

b
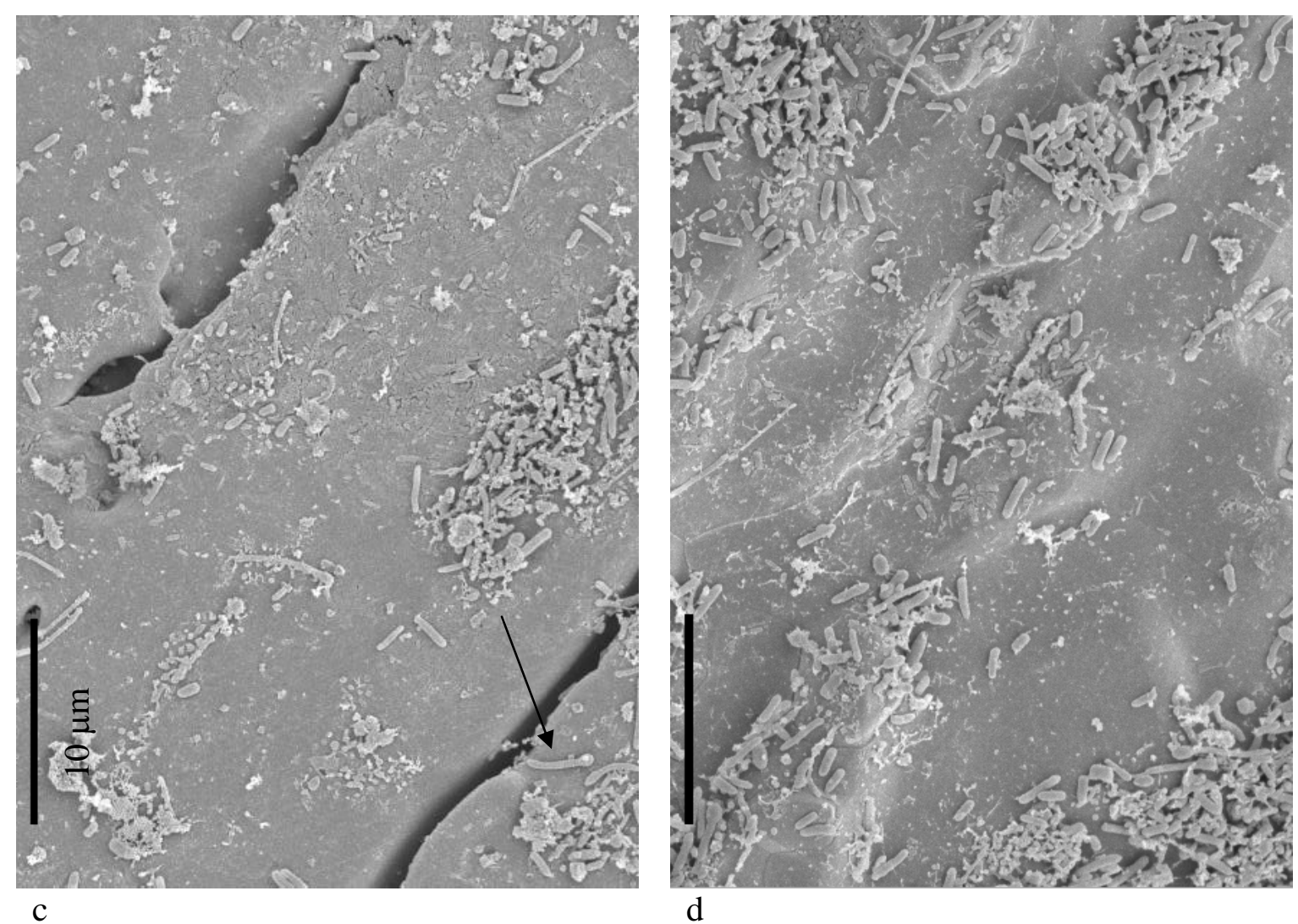

Figure 4 L. innocua biofilms after 4 days (Arrow depicts an elongated cell)

$(a \operatorname{Re}=9,500 ; b \operatorname{Re}=11,500 ; c \operatorname{Re}=13,000 ; d \operatorname{Re}=16,500)$

Page 23 of 24 

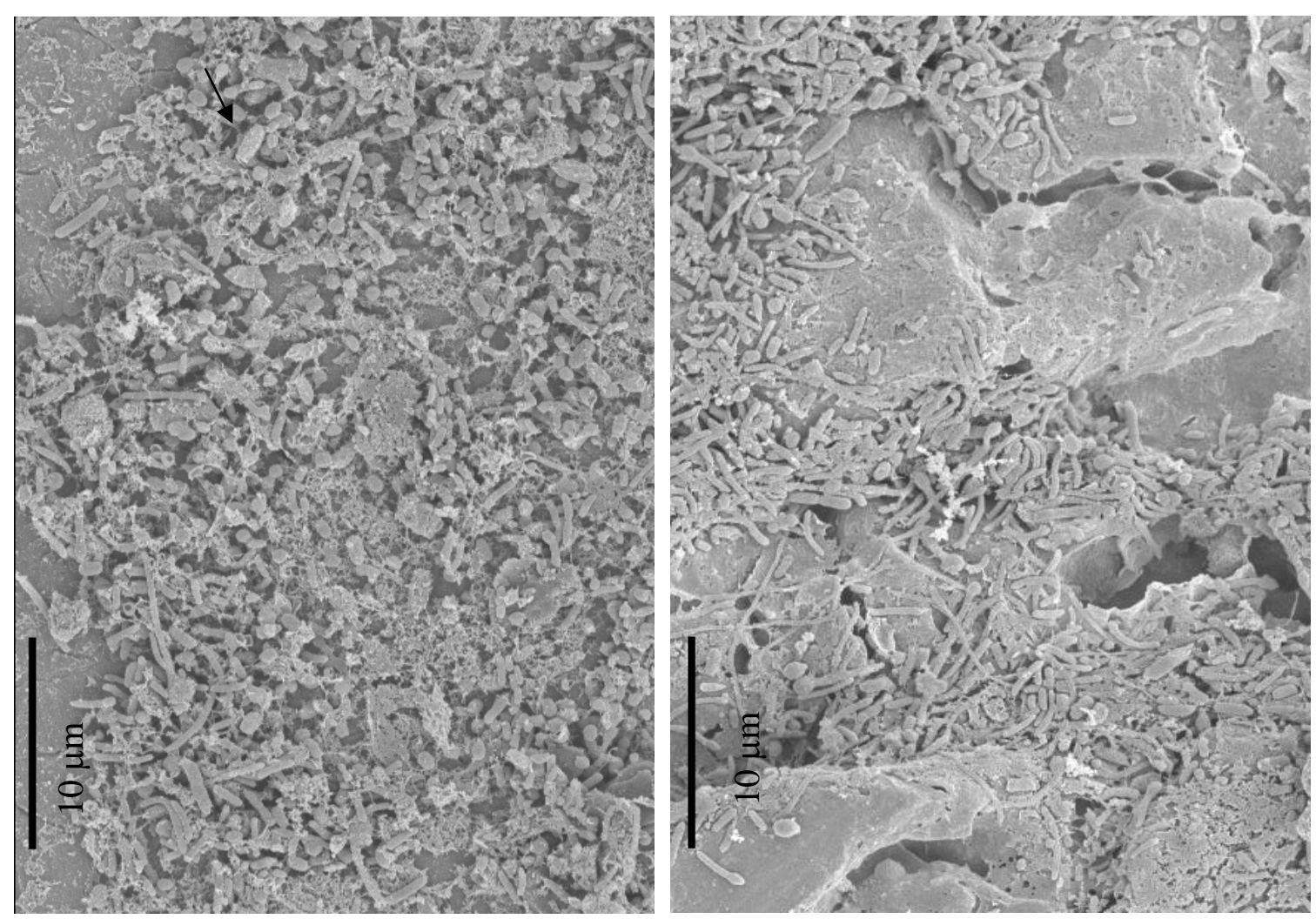

a

b
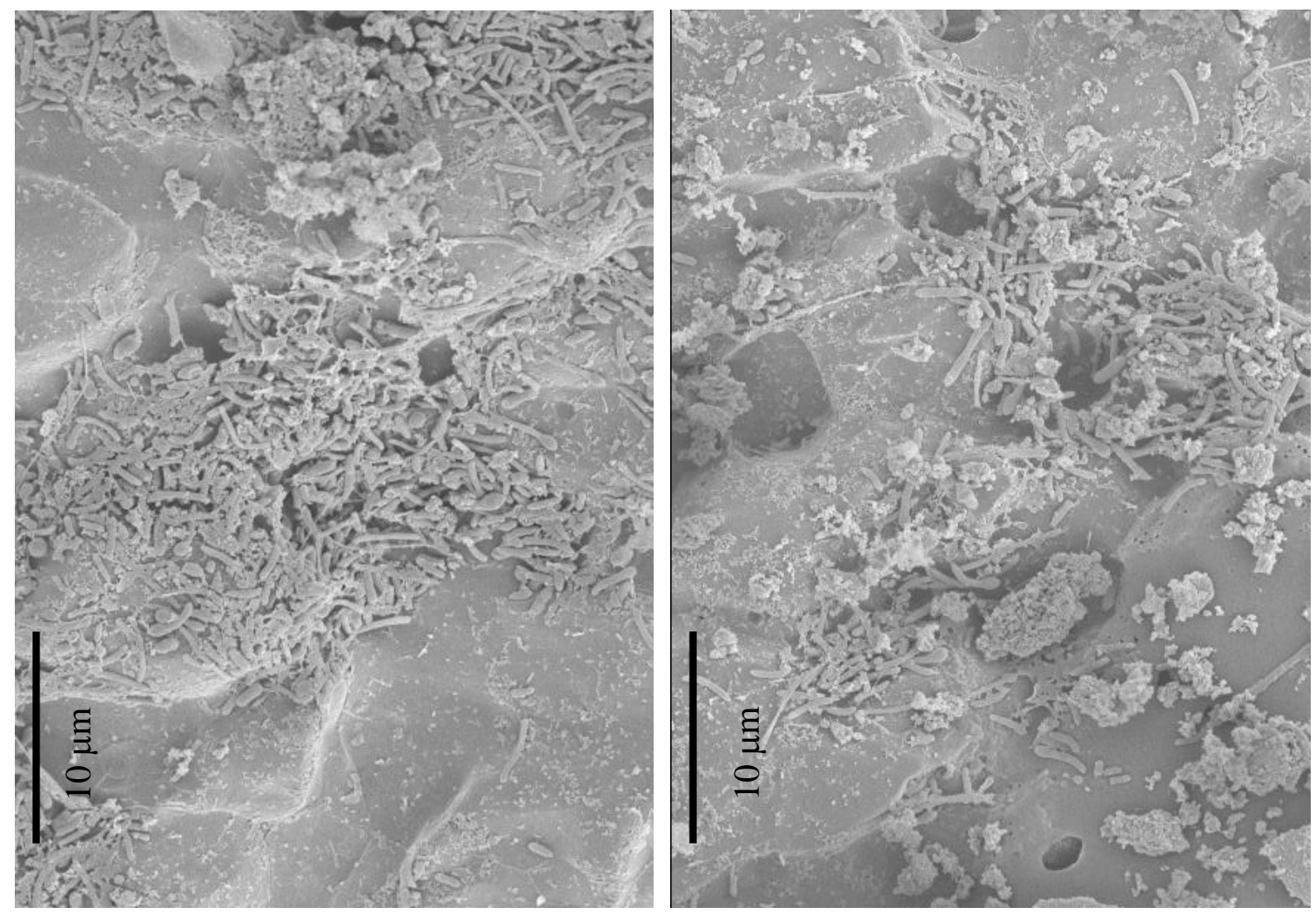

d

Figure 5 L. innocua biofilm after 7 days (Arrow depicts squat cell)

$(a \operatorname{Re}=9,500 ; b \operatorname{Re}=11,500 ; c \operatorname{Re}=13,000 ; d \operatorname{Re}=16,500)$

Page 24 of 24 